\title{
Humanizando a Prática Segura da Vacinação na Atenção Básica: um Projeto de Intervenção em Vigilância em Saúde
}

\author{
Pereira, Letícia Gabrielly Medeiros; Lino, Iven Giovana Trindade; Machado, Diego da Silva; \\ Mendonça, Margarete Kcnoh; Corona, Arminda R. de P. Del; Gamarra, Angeliza dos Santos; \\ Luz, Ananda de Mello
}

Universidade Federal do Mato Grosso do Sul — Igmde19@gmail.com

Introdução: a segurança do paciente, de acordo com a Portaria № 529 de 1 de abril de 2013, significa a redução, a um mínimo aceitável, do risco de dano desnecessário associado ao cuidado de saúde. Frente a isso foi possível visualizar uma rede de frios incorreta, a qual poderia ocasionar danos aos pacientes, pois as vacinas precisam estar armazenadas em temperaturas de $2^{\circ}$ a $8^{\circ} \mathrm{C}$ como preconizadas pelo Ministério da Saúde. Além disso, o medo, a insegurança e a tensão das crianças e seus responsáveis precisavam ser reduzidos. Objetivos: Desenvolver uma intervenção capaz de diminuir o medo, a insegurança e tensão das crianças menores de 2 anos e mães/acompanhantes frente a vacinação; Tornar a sala de vacinas um ambiente acolhedor e mais humanizado; Proporcionar uma imagem agradável por meio de uma decoração que atendesse as normas estabelecidas pelo Programa Nacional de Humanização (PNI); Realizar atendimento rico em atenção e orientações; Elaborar folder acessível e de fácil entendimento; Proporcionar uma rede de frios adequada. Metodologia: 3 momentos: 1momento Observação da tensão do acompanhante e das crianças à espera da vacina; levantamento de opiniões dos técnicos de enfermagem da sala de imunização e o enfermeiro responsável pela sala sobre as possíveis intervenções; $2^{\circ}$ momento - cobrança de solicitações de conserto da rede de frios, elaboração e apresentação do projeto às professoras do módulo; $3^{\circ}$ momento - implementação da decoração do ambiente da imunização com temas infantis; elaboração de folder que abordavam os temas: por que vacinar?, Quando vacinar? Quais vacinas devem ser tomadas?, Eventos adversos esperados e não esperados. $4^{\circ}$ momento- diálogo e entrega de folder para as mães das crianças ou acompanhantes na sala de espera da imunização da Unidade Básica de Saúde da Família Dra Jeanne Elizabeth Wanderley Tobaru - Jardim Botafogo. Resultados: Foi observado durante a execução das orientações, o interesse das mães, a busca por respostas à outras duvidas e questões que permeiam as vacinas. Também foi reconhecida pelos acompanhantes e profissionais a colaboração da decoração em diminuir a tensão do público alvo. Quanto à rede de frios, não houve resposta frente às solicitações de conserto do ar condicionado e das caixas térmicas enviadas pela gerencia da unidade para a prefeitura. Referências: MINISTÉRIO da SAÚDE. Gabinete do Ministro. Portaria $n^{\circ} 529$, de $1^{\circ}$ de abril de 2013. Institui o Programa Nacional de Segurança do Paciente (PNSP). Disponível em: < http://bvsms.saude.gov.br/bvs/saudelegis/gm/2013/prt0529_01_04_2013.html> Acesso em:20/01/2014. Descritores: Vacina; Humanização; Vigilância em Saúde; Eventos Adversos.

Pereira, Letícia Gabrielly Medeiros; Lino, Iven Giovana Trindade; Machado, Diego da Silva; Mendonça, Margarete Kcnoh; Corona, Arminda R. de P. Del; Gamarra, Angeliza dos Santos; Luz, Ananda de Mello. Humanizando a Prática Segura da Vacinação na Atenção Básica: um Projeto de Intervenção em Vigilância em Saúde.. In: Anais do Congresso Internacional de Humanidades \& Humanização em Saúde [= Blucher Medical Proceedings, num.2, vol.1]. São Paulo: Editora Blucher, 2014. ISSN 2357-7282

DOI 10.5151/medpro-cihhs-10839 